\title{
Breed comparisons and characteristics of use of livestock guarding dogs
}

JEFFREY S. GREEN AND ROGER A. WOODRUFF

\section{Abstract}

Research has shown that dogs can protect livestock from coyotes (Canis latrans), but information is lacking on comparative effectiveneas of dog breeds and on how successfully dogs are being used by livestock producers. We mailed questionnaires to 948 livestock producers in the U.S. and Canada who were likely to be users of livestock guarding dogs. Three hundred ninety-nine written responses were received reporting data on 763 dogs, almost all recognized guarding breeds. Respondents were livestock producers from 47 states and 7 provinces. Producers rated their dogs as very effective $(71 \%)$, somewhat effective $(21 \%)$, or not effective (8\%) in deterring predation; the majority (82\%) wid dogs were an economic asset. No particular breed was rated more highly, and the rate of success between males and females was not different. Fifty nonrespondents were telephoned, and although fewer of them had dogs than respondents, their rating of the dogs they used was not significantly different from that of respondents. The data indicate that, when used by producers, livestock guarding dogs are an effective method to manage predation.

Key Words: Canis latrans, coyotes, predation, predator control, sheep

Historically, in some parts of the world it was common to use dogs to protect livestock from predators, but it is a relatively novel approach for most livestock producers in the United States. During the late 1970's research was initiated in the United States by several organizations to evaluate using guarding dogs to protect livestock from coyotes (Canis latrans) and dogs. In general, dogs were capable of reducing predation on sheep in a variety of management systems (Linhart et al. 1979; McGrew and Blakesley 1982; Coppinger et al. 1983; Green and Woodruff 1983a, 1983b; Black and Green 1985).

Several breeds of dog can be used to protect livestock, but comparative information on their effectiveness is rare. In addition, use of guarding dogs by livestock producers remains poorly described. Although we conducted 2 surveys of producers who used livestock guarding dogs (Green and Woodruff 1980, Green et al. 1984), they were made early in the period that guarding dogs were being researched, and a relatively small number of producers responded ( 72 and 67, respectively). Information on breed effectiveness and how dogs are currently being used by livestock producers is of value for planning effective programs of predator management. In this paper we report the results of an extensive survey of livestock guarding dog users in North America as they relate to breed effectiveness and current use of guarding dogs.

\section{Methods}

A questionnaire was developed and sent to livestock producers whom we believed used guarding dogs. Questionnaires were also sent to each state extension service with a request that they be forwarded to producers using guarding dogs. The questionnaire asked for information on the type of livestock operation (pasture

Authors are research wildlife biologist, USDA-Agricultural Research Service and scientific aid II, University of Idaho, both at the U.S. Sheep Experiment Station, Dubois, Idaho 83423.

G. Richardson helped with the design of the study and statistics.

The authors thank each livestock producer who participated in the survey.

Manuscript accepted 5 January 1988. or rangeland) and the number of livestock involved, the type of training the $\operatorname{dog}(\mathrm{s})$ received ( 5 predefined types of training were given as choices), and whether the producer recommended the use of guard dogs.

The following was requested for each guard dog: breed, sex, and age; age when acquired; age when placed with livestock; spayed, neutered, or unaltered; not effective, somewhat effective, or very effective as a predator deterrent; economic asset, break-even, or liability; whether the dog injured sheep or bit people; whether the dog stayed with sheep rarely, usually, or most of the time; and whether the dog was aggressive toward predators and other dogs.

Questionnaires were mailed to 948 people during January to August 1986. They were sent to 47 states and 7 Canadian provinces; about 20-30 were returned as undeliverable. We telephoned 50 randomly selected nonrespondents to determine if they had guard dogs and if the evaluations of dogs were comparable to respondents.

We were interested in answering several questions. Was any breed or sex of guarding dog rated more highly? How did livestock producers rate the effectiveness of guarding dogs? Did producers consider dogs an economic asset? Under what type of grazing conditions were most dogs used? Chi-square procedures were used to analyze the data.

\section{Results and Discussion}

\section{Respondents}

We received 399 written responses reporting on 763 dogs. The nonrespondents we telephoned reported on 45 dogs. Ratings of dogs by questionnaire respondents and nonrespondents did not differ $(P>0.05)$ although fewer nonrespondents had used livestock guarding dogs. This information alleviated our concern that producers failed to respond primarily as a result of a negative experience with a guarding dog. All data reported hereafter refer to questionnaire respondents.

Three hundred thirty-three ( $90 \%)$ producers grazed their livestock primarily on pastures, and $39(10 \%)$ on rangeland. (Because some respondents did not answer all questions, totals may not equal 399.) Small pasture operations $(<50$ head of livestock, $n=$ 109) had from 4-50 head (median $=25$ ). Seventy-eight had sheep exclusively, 26 had only goats, and 5 had sheep and goats. Large pasture operations $(n=208)$ had from $56-8,000$ head (median = 200). One hundred seventy-five had sheep exclusively, 22 had only goats, and 11 had sheep and goats.

Three hundred eighteen of $322(99 \%)$ pasture operators recommended use of guard dogs, and $4(1 \%)$ did not. These producers each used from 1-20 dogs ( \pm 2$)(x \pm S D)$ and rated them as follows: 475 very effective ( $71 \%), 144$ somewhat effective $(21 \%)$, and 52 not effective (9\%).

Range operators who provided data on numbers of livestock ( $\mathrm{n}=$ 37) had from 12-16,000 head (median $=1,000$ ). Thirty-three had sheep exclusively, and 4 had only goats. Thirty-eight of 39 operators recommended the use of livestock guarding dogs, and 1 producer made no recommendation. Range producers each used from 1-12 dogs ( $3 \pm 2)$ and rated them as follows: 60 very effective (66\%), 17 somewhat effective (19\%), and 14 not effective (15\%). Ratings of dogs from small pasture operations were better than for dogs on large pasture operations or rangeland $(P<0.05)$.

Producers characterized the type of training their $\operatorname{dog}(s)$ received 
Table 1. Summary of data characterizing the liveatock guarding dope reported in the survey. (Whth the exception of $n$, all numbers are percentages).

\begin{tabular}{|c|c|c|c|c|c|c|c|c|c|}
\hline & \multirow[b]{2}{*}{$\mathbf{n}$} & \multicolumn{3}{|c|}{ Effectiveness } & \multicolumn{3}{|c|}{ Economics } & \multicolumn{2}{|c|}{ Aggressive } \\
\hline & & Very & Somewhat & Not & Asset & Breakeven & Liability & To predators & To dogs \\
\hline $\begin{array}{l}\text { Pyrenees } \\
\text { Komondor } \\
\text { Akbash } \\
\text { Anatolian } \\
\text { Maremma } \\
\text { Shar } \\
\text { Kuvasz } \\
\text { Hybrid* } \\
\text { Other }\end{array}$ & $\begin{array}{r}437 \\
138 \\
62 \\
56 \\
20 \\
11 \\
7 \\
23 \\
9\end{array}$ & $\begin{array}{l}71 \\
69 \\
69 \\
77 \\
70 \\
40 \\
57 \\
87 \\
43\end{array}$ & $\begin{array}{r}22 \\
1 \\
22 \\
13 \\
20 \\
30 \\
29 \\
4 \\
29\end{array}$ & $\begin{array}{r}7 \\
12 \\
9 \\
10 \\
10 \\
30 \\
14 \\
9 \\
28\end{array}$ & $\begin{array}{l}83 \\
82 \\
71 \\
82 \\
84 \\
50 \\
80 \\
84 \\
20\end{array}$ & $\begin{array}{r}11 \\
8 \\
12 \\
8 \\
5 \\
0 \\
0 \\
5 \\
20\end{array}$ & $\begin{array}{r}6 \\
10 \\
12 \\
10 \\
11 \\
50 \\
20 \\
11 \\
60\end{array}$ & $\begin{array}{r}95 \\
94 \\
100 \\
96 \\
94 \\
88 \\
100 \\
95 \\
83\end{array}$ & $\begin{array}{r}67 \\
77 \\
92 \\
86 \\
94 \\
89 \\
67 \\
85 \\
100\end{array}$ \\
\hline Total & 763 & 71 & 21 & 8 & 82 & 9 & 9 & 95 & 74 \\
\hline
\end{tabular}

*Hybrids were crosses of 2 or more guarding breeds.

Table 1. cont.

\begin{tabular}{|c|c|c|c|c|c|c|c|c|}
\hline \multirow[b]{2}{*}{ Breed } & \multicolumn{3}{|c|}{ Problems } & \multicolumn{3}{|c|}{ Stays with Sheep } & \multirow{2}{*}{$\begin{array}{c}\text { Dog injured } \\
\text { sheep }\end{array}$} & \multirow{2}{*}{$\begin{array}{l}\text { Dog bit } \\
\text { people }\end{array}$} \\
\hline & Major & Minor & None & Mostly & Usually & Rarely & & \\
\hline $\begin{array}{l}\text { Pyrenees } \\
\text { Komondor } \\
\text { Akbash } \\
\text { Anatolian } \\
\text { Maremma } \\
\text { Shar } \\
\text { Kuvasz } \\
\text { Hybrid* } \\
\text { Other }\end{array}$ & $\begin{array}{l}11 \\
14 \\
15 \\
10 \\
18 \\
20 \\
14 \\
19 \\
33\end{array}$ & $\begin{array}{l}47 \\
48 \\
49 \\
48 \\
24 \\
40 \\
86 \\
38 \\
50\end{array}$ & $\begin{array}{r}42 \\
38 \\
36 \\
42 \\
58 \\
40 \\
0 \\
43 \\
17\end{array}$ & $\begin{array}{l}53 \\
50 \\
71 \\
69 \\
79 \\
30 \\
33 \\
70 \\
33\end{array}$ & $\begin{array}{l}24 \\
23 \\
12 \\
16 \\
16 \\
20 \\
33 \\
13 \\
17\end{array}$ & $\begin{array}{r}23 \\
27 \\
17 \\
15 \\
5 \\
50 \\
34 \\
17 \\
50\end{array}$ & $\begin{array}{l}7 \\
24 \\
20 \\
14 \\
20 \\
33 \\
40 \\
18 \\
43\end{array}$ & $\begin{array}{r}4 \\
17 \\
6 \\
9 \\
5 \\
25 \\
0 \\
0 \\
29\end{array}$ \\
\hline Total & 13 & 46 & 41 & 55 & 22 & 22 & 14 & 7 \\
\hline
\end{tabular}

Hybrids were crosses of 2 or more guarding breeds.

as follows: (1) dog raised exclusively with sheep or goats, human contact minimized, $57 \%$; (2) dog raised in a loose association with sheep or goats, $30 \%$; (3) dog received obedience training, $2 \%$; (4) no specific rearing or training program, $6 \%$; and $(5)$ other, $5 \%$. Many producers $(n=70)$, especially those who raised more than $1 \mathrm{dog}$, selected more than 1 type of training.

\section{Dogs}

Over $95 \%$ of the dogs were recognized guarding breeds with Great Pyrenees and Komondor most common (Table 1). Despite the indication that mixed-breed dogs of nontypical guarding stock may be effective guardians (Black and Green 1985), few were identified in this survey.

The rate of success among Pyrenees, Komondor, Akbash, Anatolians, Maremma, and hybrids was not different (sample size was insufficient to allow comparison with the other breeds) nor was there a difference between the success of males and females or intact and neutered dogs $(P>0.05)$. Forty-six percent of the dogs were males, and $29 \%$ of the dogs were neutered. Most of the dogs were aggressive to predators and other dogs. More Komondors bit people than did Pyrenees, Akbash, or Anatolians, and fewer Pyrenees injured livestock than did Komondors, Akbash, or Anatolians $(P<0.01)$.

Most dogs (64\%) were used on large (>50 head of livestock) or small pasture $(23 \%)$ operations rather than range operations (13\%). The majority of dogs stayed with sheep "most of the time" and were considered an economic asset (Table 1).

Fifty percent of the dogs were acquired by 3 months-of-age, and $82 \%$ were acquired by 1 year-of-age. The remaining dogs $(n=117)$ were acquired between 13 and 84 months-of-age. There was no difference in success between dogs acquired at $\leq 2$ months and those acquired at $>2$ months-of-age $(P>0.05)$. However, dogs that were reared with livestock from the time they were $\leq 2$ months old $(n=280)$ had a higher rate of success than those that were older than 2 months-of-age $(n=227)$ when placed with livestock $(P<0.01)$. Dogs ranged in age from 4-168 months with $64 \%$ of the dogs 3 years old or less.

\section{Conclusions}

Based on the results of this and our previous surveys (Green and Woodruff 1980, Green et al. 1984), the use of livestock guarding dogs is increasing, and most producers who use dogs consider them effective. No particular breed or sex was rated more highly, but breeds differed in frequency of biting people and injuring livestock. Success was higher when dogs were reared with livestock from the time they were $\leq 2$ months old. It appears that livestock producers who face unresolved predation problems may do well to consider the use of guarding dogs.

\section{Literature Cited}

Black, H.L., and J.S. Green. 1985. Navajo use of mixed-breed dogs for management of predators. J. Range Manage. 38:11-15.

Coppinger, R., J. Lorenz, and L. Coppinger. 1983. Introducing livestock guarding dogs to sheep and goat producers, p. 129-132. In: D.J. Decker (ed.), Proc. first eastern wildl. damage control conf., Cornell Univ., Ithaca, N.Y.

Green, J.S., and R.A. Woodruff. 1980. Is predator control going to the dogs? Rangelands 2:187-189.

Green, J.S., and R.A. Woodruff. 1983a. The use of three breeds of dog to protect rangeland sheep from predators. Appl. An. Ethol. 11:141-161.

Green, J.S., and R.A. Woodruff. 1983b. The use of Eurasian dogs to protect sheep from predators in North America: a summary of research at the U.S. Sheep Experiment Station, p. 119-124. In: D.J. Decker (ed.), Proc. first eastern wildl. damage control conf., Cornell, Univ., Ithaca, N.Y. 
Green, J.S., R.A. Woodruff, and T.T. Tueller. 1984. Livestock-guarding dogs for predator control: costs, benefits, and practicality. Wildl. Soc. Bull. 12:44-50.

Linhart, S.B., R.T. Sterner, T.C. Carrigan, and D.R. Henne. 1979. Komondor guard dogs reduce sheep losses to coyotes: a preliminary evaluation. J. Range Manage. 32:238-241.
McGrew, J.C., and C.S. Blakesley. 1982. How Komondor dogs reduce sheep losses to coyotes. J. Range Manage. 35:693-696. 